\title{
Further tests of the HYPROP evaporation method for estimating the unsaturated soil hydraulic properties
}

\author{
Camila R. Bezerra-Coelho ${ }^{1}$, Luwen Zhuang ${ }^{2}$, Maria C. Barbosa ${ }^{1}$, Miguel Alfaro Soto ${ }^{3}$, \\ Martinus Th. van Genuchten ${ }^{2,}$ \\ ${ }^{1}$ Department of Civil Engineering, Federal University of Rio de Janeiro, UFRJ, Rio de Janeiro, RJ, Brazil. \\ ${ }^{2}$ Department of Earth Sciences, Utrecht University, Utrecht, Netherlands. \\ ${ }^{3}$ Department of Applied Geology, São Paulo State University, UNESP, Rio Claro, SP, Brazil. \\ ${ }^{4}$ Department of Nuclear Engineering, Federal University of Rio de Janeiro, UFRJ, Rio de Janeiro, RJ, Brazil. \\ *Corresponding author. E-mail: rvangenuchten@hotmail.com
}

\begin{abstract}
Many soil, hydrologic and environmental applications require information about the unsaturated soil hydraulic properties. The evaporation method has long been used for estimating the drying branches of the soil hydraulic functions. An increasingly popular version of the evaporation method is the semi-automated HYPROP ${ }^{\mathcal{O}}$ measurement system (HMS) commercialized by Decagon Devices (Pullman, WA) and UMS AG (München, Germany). Several studies were previously carried out to test the HMS methodology by using the Richards equation and the van-Genuchten-Mualem (VG) or Kosugi-Mualem soil hydraulic functions to obtain synthetic data for use in the HMS analysis, and then to compare results against the original hydraulic properties. Using HYDRUS-1D, we carried out independent tests of the HYPROP system as applied to the VG functions for a broad range of soil textures. Our results closely agreed with previous findings. Accurate estimates were especially obtained for the soil water retention curve and its parameters, at least over the range of available retention measurements. We also successfully tested a dual-porosity soil, as well as an extremely coarse medium with a very high van Genuchten $n$ value. The latter case gave excellent results for water retention, but failed for the hydraulic conductivity. In many cases, especially for soils with intermediate and high $n$ values, an independent estimate of the saturated hydraulic conductivity should be obtained. Overall, the HMS methodology performed extremely well and as such constitutes a much-needed addition to current soil hydraulic measurement techniques.
\end{abstract}

Keywords: Soil hydraulic properties; Evaporation method; HYPROP; HYDRUS-1D; van Genuchten-Mualem equations.

\section{INTRODUCTION}

Reliable data about the unsaturated soil hydraulic properties are crucial for many hydrologic, agricultural and environmental applications. A large number of experimental methodologies have been developed and tested over the years to estimate the soil water retention and unsaturated soil hydraulic conductivity (Dane and Hopmans, 2002; Klute (Ed.), 1986). A direct approach for the soil water retention function is to measure a series of water content $(\theta)$ and pressure head $(h)$ pairs, and then to fit a particular function to the data. Direct measurement techniques include methods using a hanging water column or sand box, pressure cells, pressure plate extractors, suction tables, soil freezing, and many other approaches as reviewed by Looney and Falta (Eds.) (2000), Dane and Hopmans (2002), and Bittelli and Flury (2009), among others. Once the pairs of $\theta$ and $h$ data are obtained, the results may be analyzed in terms of specific analytical functions such as those by Brooks and Corey (1964), van Genuchten (1980), Fredlund and Xing (1994), Kosugi (1996), or Assouline et al. (1998). Several convenient software packages are available for this purpose (van Genuchten et al., 1991; Wraith and Or, 1998). Alternatively, the data could be analyzed without assuming specific analytical functions, for example by using linear, cubic spline or other interpolation techniques (Bitterlich et al., 2004; Kastanek and Nielsen, 2001).

Similar direct approaches involving pairs of conductivity and pressure head or water content data are in principle also possible for the $K(h)$ or $K(\theta)$ functions (Dane and Hopmans, 2002; Klute and Dirksen, 1986), including for the saturated hydraulic conductivity, $K_{s}$. The latter parameter can be measured in the laboratory using a variety of constant or falling head methods, and in the field using single or double ring infiltrometers, constant head permeameters, and various auger-hole and piezometer methods (Dane and Topp (Eds.), 2002). Unfortunately, pairs of $K(h)$ or $K(\theta)$ data are not easily obtained in the very dry range unless more specialized approaches are used such as hot-air, centrifugation or dew-point techniques (Arya, 2002; Nimmo et al., 2002; Scanlon et al., 2002). Consequently, unsaturated hydraulic conductivity properties often are still estimated using inverse or parameter estimation procedures.

Parameter estimation methods generally involve measurements of several capacity and flow attributes (e.g., water contents, pressure heads, boundary fluxes), which are then used in combination with a numerical solution of the Richards equation to obtain estimates of the hydraulic parameters in the adopted soil hydraulic functions. Popular methods include one-step and multi-step outflow methods (Hopmans et al., 2002; Kool et al., 1987; van Dam et al., 1994), tension infiltrometer methods (Šimůnek et al., 1998a) and evaporation methods (Šimůnek et al., 1998b), although many other laboratory and field methods also exist or can be similarly employed (Hopmans et al., 2002).

One frequently used approach is the evaporation method, stemming from the early work by Gardner and Miklich (1962) using horizontal columns, and subsequent modifications by Wind (1968) and others. Measurements of the evaporation rate and tension at multiple depths in the sample permitted the simultaneous direct estimation of the water retention and hydraulic conductivity. Key contributions have been by Halbertsma (1996), Klute and Dirksen (1986), Becher (1970), Plagge (1991), 
Wendroth et al. (1993), Bertuzzi and Voltz (1997), and many others, including analyses of the data using parameters estimation approaches (Šimůnek et al., 1998b, Iden and Durner, 2008). An increasingly popular version of the evaporation method is the HYPROP $^{\mathcal{O}}$ measurement system (further referred to here as HMS), which allows semi-automated direct measurements of water retention and conductivity pairs over a relatively wide range of pressure head values (Peters and Durner, 2008; Peters et al., 2015; Schindler et al., 2010a, b, and others). The HMS approach has been commercialized jointly by Decagon Devices (Pullman, WA, USA) and UMS AG (Munich, Germany), now known as the METER group. The commercial system involves pressure head measurements versus time at two depths within a short $5-\mathrm{cm}$ soil sample as water evaporates from its surface, with the evaporation rate determined by weighing the column.

Several studies have been carried out to test the HYPROP evaporation approach against multistep outflow and other methods (e.g., Schelle et al., 2010; Zhuang et al., 2017). Peters and Durner (2008) and Peters et al. (2015) tested the HMS approach assuming synthetic (virtual) data for the two pressure heads within the sample, as well as for the evaporation rate (and hence the sample weight), as a function of time as generated with numerical solutions of the Richards equation. Peters and Durner (2008) used for this purpose the hydraulic functions of van Genuchten-Mualem (1980), while Peters et al. (2015) used the equations of Kosugi (1996) as well as the PDI model of Peters and colleagues (Iden and Durner, 2014; Peters, 2013, 2014) to account for the effects of film, corner and isothermal vapor flow in very dry soils.

In this study we follow a very similar approach using the standard van Genuchten-Mualem approach to provide an independent test of the HYPROP evaporation method. HMS performance is studied in particular for a broad range of soils having different van Genuchten $\alpha$ and $n$ parameters, as well as for a dual-porosity medium as described with the composite hydraulic functions of Durner (1994). We first give a very brief description of the HYPROP evaporation method. The HYDRUS-1D software package (Šimůnek et al., 2016) is used next to generate virtual (synthetic) pressure heads in the column, as well as the evaporation rate (and hence the weight of the soil sample), as a function of time. The data are subsequently used in the HYPROP-Fit software (Pertassek et al., 2015) to estimate the hydraulic properties of the assumed porous media, thus providing a means for testing HMS performance. We also investigated the use of different potential evaporation rates, thus providing tests of the robustness of the HYPROP method for different soil types and environmental conditions.

\section{THE HYPROP MEASUREMENT SYSTEM (HMS)}

The HMS setup involves pressure head measurements at two depths within a standard 5-cm short soil column as water evaporates from the sample surface. Water contents and fluxes are determined by weighing the sample. Measured pressure heads, water contents, and evaporation fluxes are subsequently used to derive the water retention and unsaturated hydraulic conductivity functions (Pertassek et al., 2015; Peters and Durner, 2008; Schindler et al., 2010a). The measurement range at the wet side is restricted by limitations of pressure transducers to accurately register very small pressure head differences, reason why it is often recommended to measure the saturated hydraulic conductivity independently. At the dry side limitations are due to water cavitation in the tensiometers, usually at about $-800 \mathrm{~cm}$. Improved tensiometers are now being used that resist cavitation to pressure heads as low as $-3000 \mathrm{~cm}$ or more (Schindler et al., 2010a, b). Major advantages of the HYPROP method are its automation once the system is installed, and the fact that pairs of $\theta(h)$ and $K(h)$ are being generated. The latter means that no preselected functional forms of the water retention and/or conductivity curve (such as those the Brooks and Corey or van Genuchten-Mualem equations) need to be used. Once the data are obtained, any set of hydraulic functions could potentially be applied to the data.

Figure 1 shows the setup of the standard HMS system (Schindler et al., 2010a), sometimes referred to also as the simplified evaporation method, SEM. Pressure heads versus time are recorded at two locations $(1.25 \mathrm{~cm}$ and $3.75 \mathrm{~cm}$ from the evaporating surface), while the evaporation rate is measured

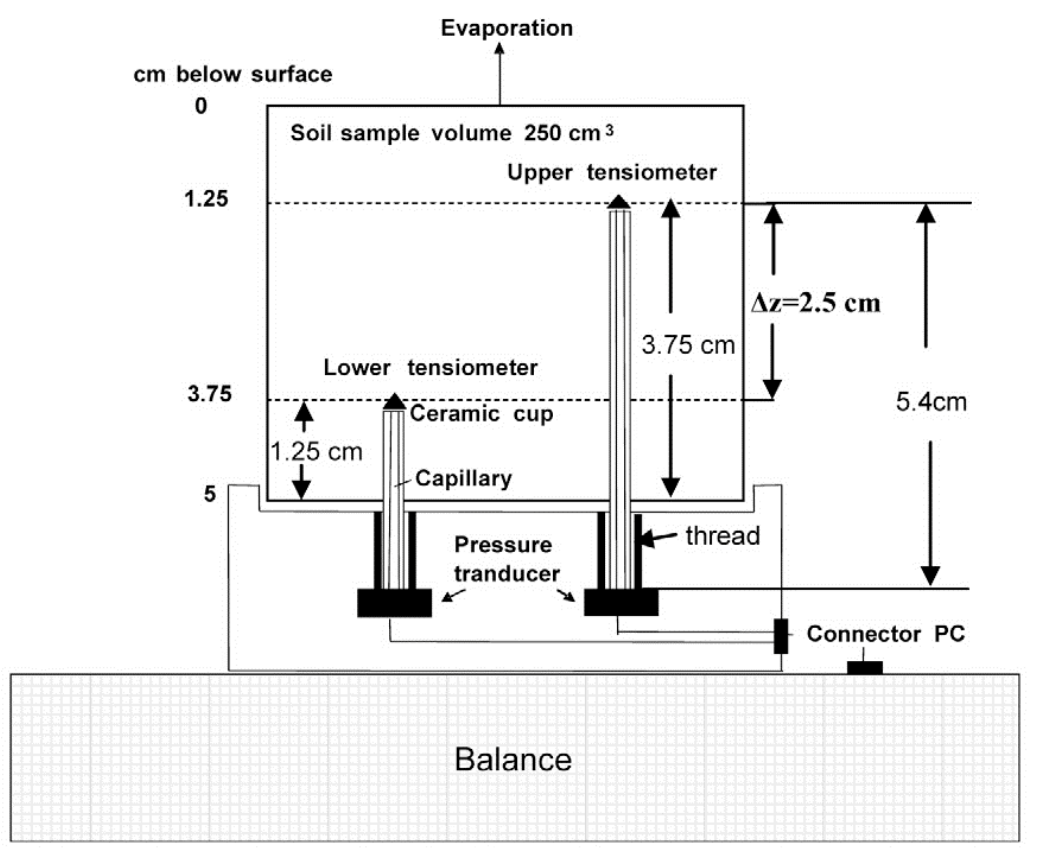

Fig. 1. Schematic of the HYPROP measurement system, HMS (after Schindler et al., 2010a). 
Table 1. Values of the soil hydraulic parameters assumed in this study for relatively fine-textured (F), medium-textured (M), coarsetextured (C), and very coarse-textured (VC) soils, and for three medium-textured media (M1, M2, M3) having different pore- or particlesize distributions (psd) as reflected by the VG parameter $n$.

\begin{tabular}{|c|c|c|c|c|c|c|c|}
\hline Case & Soil texture & $\begin{array}{c}\theta_{r} \\
\left(\mathrm{~cm}^{3} / \mathrm{cm}^{3}\right)\end{array}$ & $\begin{array}{c}\theta_{s} \\
\left(\mathrm{~cm}^{3} / \mathrm{cm}^{3}\right)\end{array}$ & $\begin{array}{c}\alpha \\
\left(\mathrm{cm}^{-1}\right)\end{array}$ & $\begin{array}{c}n \\
(-)\end{array}$ & $\begin{array}{c}K_{s} \\
(\mathrm{~cm} / \mathrm{day})\end{array}$ & $\begin{array}{c}L \\
(-)\end{array}$ \\
\hline \multicolumn{7}{|c|}{ Effect of soil texture (fine to very coarse) } \\
\hline F & Fine & 0.0 & 0.500 & 0.0080 & 1.30 & 10.0 & 0.50 \\
\hline M & Medium & 0.0 & 0.450 & 0.0160 & 1.80 & 50.0 & 0.50 \\
\hline C & Coarse & 0.0 & 0.400 & 0.0320 & 2.50 & 250.0 & 0.50 \\
\hline VC & Very coarse & 0.1 & 0.400 & 0.0219 & 10.0 & 1000.0 & 0.50 \\
\hline \multicolumn{7}{|c|}{} \\
\hline M1 & Effect of the pore-size distribution, psd (broad to narrow) & & 0.50 \\
\hline M2 & Medium psd & 0.0 & 0.450 & 0.016 & 1.30 & 50.0 & 0.50 \\
\hline M3 & Narrow psd & 0.0 & 0.450 & 0.016 & 1.80 & 50.0 & 0.50 \\
\hline
\end{tabular}

by repeated weighting. Measurements continue until the upper tensiometer reaches some limiting value (Schindler et al., 2010a). The data are subsequently analyzed from the average water content, the pressure head readings of the two tensiometers, and the mean total head gradients between the two tensiometers. We refer to Schindler et al $(2010 \mathrm{a}, \mathrm{b})$ and Peters et al. (2015) for detailed descriptions of the setup and the data analysis.

The data in our study were generated by running HYDRUS-1D simulations, very similar as done by Peters and Durner (2008) and Peters et al. (2015). For most of the simulations we used a spatial discretization involving 61 nodes, with mesh refinement near the sample upper surface to accommodate higher local pressure head gradients during the simulations. More elements were used for soils having a narrow poresize distribution (i.e., large van Genuchten $n$ values). In most cases we imposed a relatively high potential evaporation rate of $1 \mathrm{~cm} /$ day, thus assuming that evaporation may have been enhanced by ventilation (e.g., Wendroth et al., 1993). Imposing lower potential evaporation rates (e.g., 0.4 or $0.2 \mathrm{~cm} /$ day) were not found to have significant effects on the results, except for slowing the experiments. The potential evaporation rate was implemented as a system-dependent boundary conditions until a critical pressure head, $h_{c r i t}$, was reached, after which a constant pressure head is imposed. We used for most cases the HYDRUS-1D default value of $-10^{5} \mathrm{~cm}$ for $h_{\text {crit }}$, except for very coarse-textured samples for which we used less extreme values to limit numerical problems. The bottom boundary was a zero fluid flux condition, while as initial condition we used an equilibrium profile with a pressure head of $4 \mathrm{~cm}$ at the bottom of the $5 \mathrm{~cm}$ sample. We assumed that all of the virtual experiments were carried out at a constant temperature of $20^{\circ} \mathrm{C}$. Average water contents of the sample as needed for the HMS analysis were estimated from the initial water content and the calculated evaporation rates.

Soil hydraulic properties for most scenarios were described using the standard van Genuchten-Mualem formulation given by (van Genuchten, 1980)

$S_{e}(h)=\frac{\theta(h)-\theta_{r}}{\theta_{s}-\theta_{r}}=\frac{1}{\left[1+|\alpha h|^{n}\right]^{m}}$
$K\left(S_{e}\right)=K_{s} S_{e}{ }^{L}\left[1-\left(1-S_{e}^{1 / m}\right)^{m}\right]^{2}$

where $S_{e}$ is effective saturation [-], $\theta_{s}$ and $\theta_{r}$ are the saturated and residual water contents, respectively $\left[\mathrm{L}^{3} \mathrm{~L}^{-3}\right], K_{s}$ is the saturated hydraulic conductivity $\left[\mathrm{LT}^{-1}\right], \alpha\left[\mathrm{L}^{-1}\right]$ and $n[-]$ are semiempirical shape parameters, $m=1-1 / n$, and $L$ is a poreconnectivity parameter [-], which we fixed in the HYDRUS1D simulations at 0.5 following the original study by Mualem (1976).

We explored the effects of a wide range of hydraulic parameters values on the HMS results, notably by varying values of the hydraulic parameters $\alpha$ and $n$. Table 1 lists only those examples that are specifically discussed in this paper. The examples in Table 1 are separated into two sets covering (1) a range of values typical of fine-, medium-, coarse-, and very coarsetextured soils, and (2) several medium-textured samples having increasingly narrow pore-size distributions as reflected by increasingly larger $n$ values. Our study assumed the residual water content, $\theta_{r}$, to be zero, except for the very coarse (VC) example. The analyses would be essentially the same if fixed non-zero $\theta_{r}$ values were used. We fixed $\theta_{r}$ in our study by reasoning that additional independent water retention measurements often are needed (especially for fine-textured media) to define the very dry side of the hydraulic functions, such as conventional pressure plate extractor and/or WP4 dew-point potentiometer measurements (e.g., Gubiani et al., 2012). We note that Peters et al. (2015) were also concerned about possible vapor flow and other complications in the very dry side of the hydraulic properties. We decided not to address these issues within the context of the HMS studies, but to focus instead only on the hydraulic properties at relatively wet and intermediate water contents.

We additionally explored the performance of a dual-porosity soil whose hydraulic properties are described using the composite hydraulic functions of Durner (1994) and Priesack and Durner (2006) for $S_{e}(h)$ and $K\left(S_{e}\right)$ given by

$S_{e}(h)=\frac{\theta(h)-\theta_{r}}{\theta_{s}-\theta_{r}}=\frac{w_{1}}{\left[1+\left|\alpha_{1} h\right|^{n_{1}}\right]^{m_{1}}}+\frac{w_{2}}{\left[1+\left|\alpha_{2} h\right|^{n_{2}}\right]^{m_{2}}}$ 
respectively, where $S_{i}, \alpha_{i}, n_{i}$, and $m_{i}(i=1,2)$ are the same as in (1) and (2) for the macropore and micropore regions, respectively (or of the fracture and matrix regions if interpreted for unsaturated fractured rock), while $w$ defines the division of the porous medium in macropore and micropore regions. Values of the various parameters used in Eqs. (3) and (4) were $\theta_{r}=0.10$, $\theta_{s}=0.50, L=0.50, K_{s}=50 \mathrm{~cm} \mathrm{~d}^{-1}, w_{1}=w_{2}=0.5, \alpha_{1}=0.2 \mathrm{~cm}^{-1}$, $n_{1}=2.5, \alpha_{2}=0.002 \mathrm{~cm}^{-1}$, and $n_{2}=2.0$.

Once the pressure heads and actual evaporation rates (and hence sample weights) were generated using HYDRUS-1D, the HYPROP-Fit analysis was applied to the synthetic numerical data, leading to estimates of the original soil hydraulic parameters. HYPROP-Fit used the root mean square error (RMSE) to quantify differences between the synthetic $\left(y_{i}\right)$ water retention or unsaturated hydraulic conductivity data, and calculated values $\left(y_{i}^{c}\right)$ based on the fitted VG curves. RMSE values were calculated using

$$
R M S E=\sqrt{\sum_{i=1}^{n_{p}} \frac{1}{n_{p}}\left(y_{i}^{c}-y_{i}\right)^{2}}
$$

where $n_{p}$ is the number of data points, and $y_{i}$ refers to either water content, $\theta_{i}$, or the logarithm of the unsaturated hydraulic conductivity, $\log \left(K_{i}\right)$.

\section{RESULTS AND DISCUSSION}

Figure 2, 3 and 4 show results for, respectively, the finetextured $(\mathrm{F})$, medium-textured $(\mathrm{M})$ and coarse-textured $(\mathrm{C})$ soils as identified in Table 1. The top left plot in each figure shows calculated pressure heads, $h_{1}(t)$ and $h_{2}(t)$, of the top and lower tensiometers, respectively, of the HMS setup, while the top right plot shows the cumulative actual evaporation rate (or cumulative weight loss per $\mathrm{cm}^{2}$ sample area), $W(t)$, as obtained with HYDRUS-1D. Calculated pressure heads and evaporation
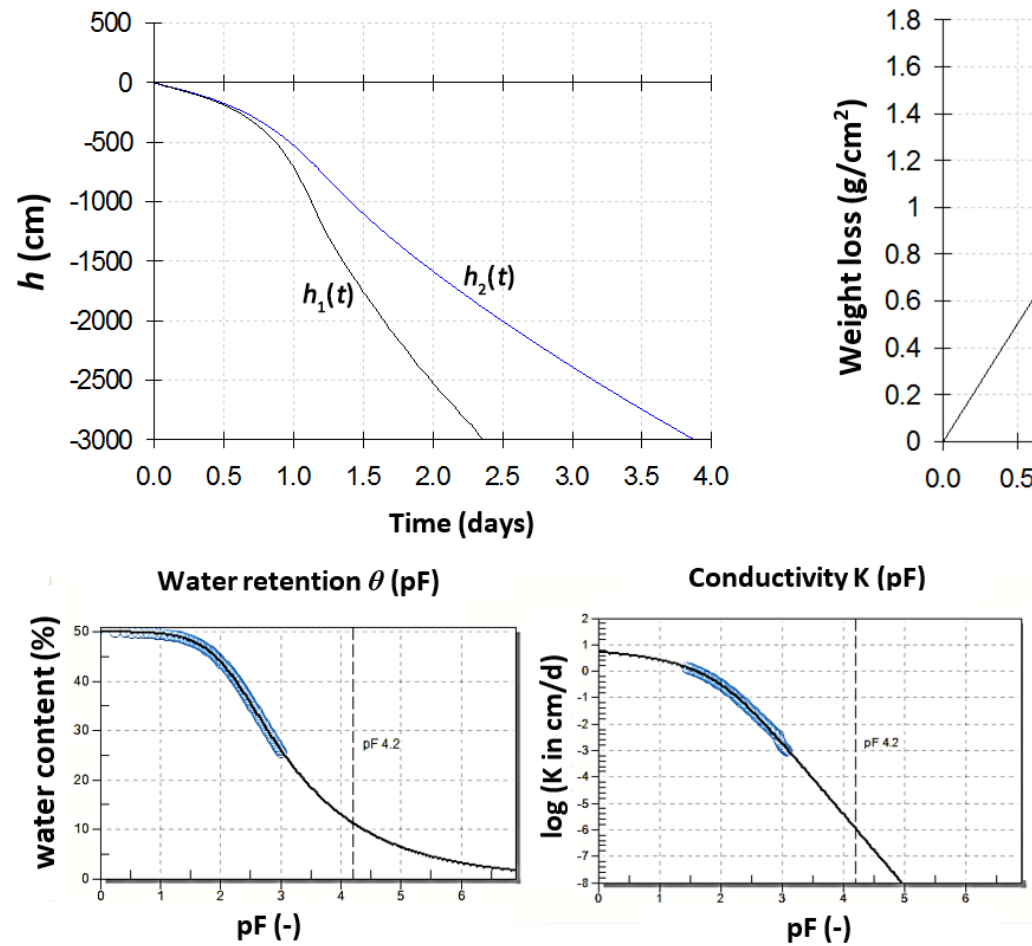

rates were obtained at regular time intervals (e.g., every 10 seconds during the first hour, every 10 minutes during the next 9 hours, and every two hours after 10 hours). Using values at regular time intervals, as compared to irregular HYDRUS-1D output times resulting from the self-adjusting numerical time stepping scheme, was found to produce smoother values of the pressure heads and evaporation rates versus time, leading to more accurate HMS results. Calculated values of the pressure heads (as equivalent suctions) and sample weights were subsequently inserted in the HYPROP-Fit software (Pertassek et al., 2015 ) to generate the water retention and hydraulic conductivity data as shown in the bottom plots of Figures 2, 3 and 4. Those plots also include the HMS fitted complete VG hydraulic functions.

Figure 2 shows the HMS estimated soil hydraulic properties values and fitted VG hydraulic functions for the fine-textured soil. As to be expected, the HMS estimated retention data cover a limited range of water contents because of limitations imposed on possible tensiometer data. Still the HMS estimated VG retention parameter values (Table 2) show very good agreement with the original values (Table 2). Estimated values for the saturated conductivity $\left(K_{s}\right)$ and the pore connectivity parameter $(L)$ were reasonably close to the true values. Fixing $K_{s}$ to the assumed synthetic value of $10 \mathrm{~cm} /$ day produced a much-improved value of $L$.

HMS water retention results for the medium-textured soil (M) in Figure 3 show a very nice coverage of the water contents, while the fitted water retention parameters were again essentially identical to the originally assumed values (Table 2). The HMS hydraulic conductivity values and fitted curve function were also in excellent agreement with the original values. In this case there was little reason to fix $K_{s}$ to the true value since both $K_{s}$ and $L$ were estimated very well. This shows that the HMS approach worked well for the medium-textured soil, without an obvious need to obtain independent estimates of $K_{s}$.

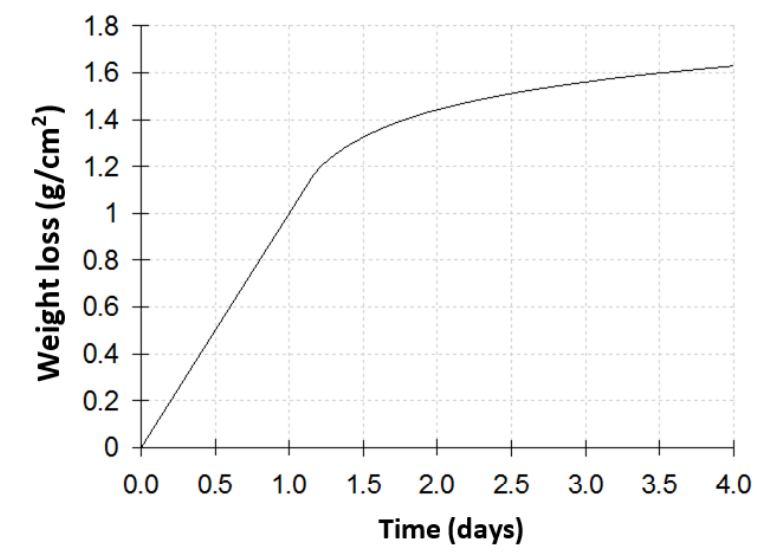

Time (days)

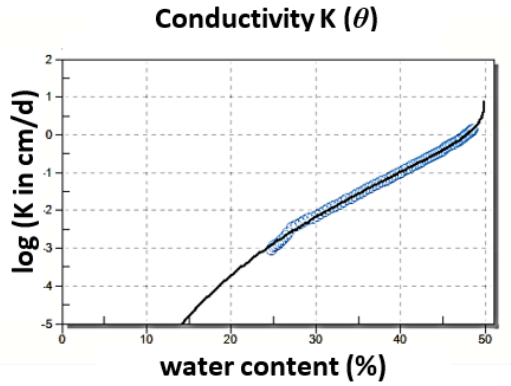

Fig. 2. HYDRUS-1D predictions of the pressure heads $h_{1}(t)$ and $h_{2}(t)$ and the cumulative weight loss $W(t)$ (top plots) for the fine-textured soil (F) obtained using the VG parameter values listed in Table 1, and plots of the HMS generated water retention and hydraulic conductivity data, together with the HYPROP-Fit estimated VG hydraulic functions using the parameters for case FH-1 (Table 2). 

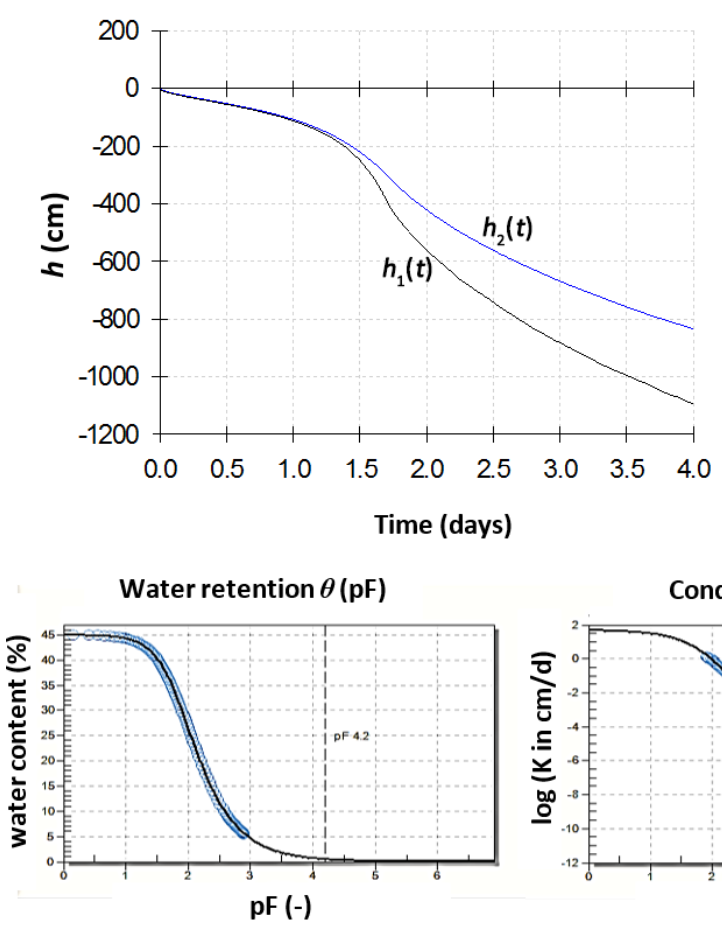
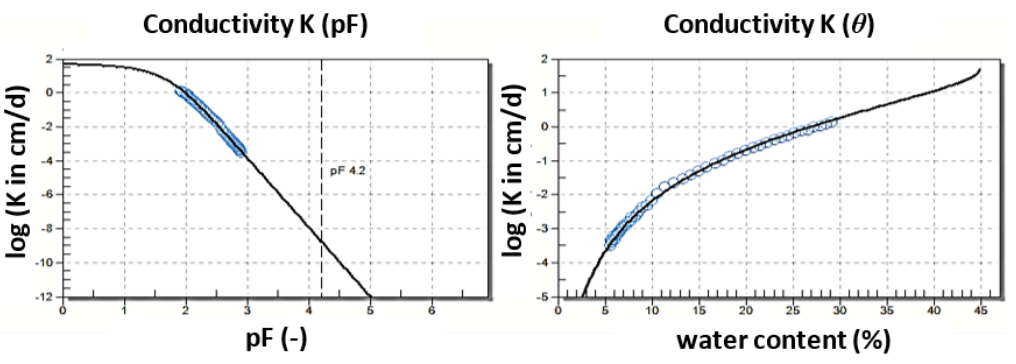

Fig. 3. HYDRUS-1D predictions of the pressure heads $h_{1}(t)$ and $h_{2}(t)$ and the weight loss $W(t)$ (top plots) for the medium-textured soil (M) obtained using the VG parameter values listed in Table 1, and plots of the HMS generated water retention and hydraulic conductivity data, together with the HYPROP-Fit estimated VG hydraulic functions using the parameters for case MH-1 (Table 2).
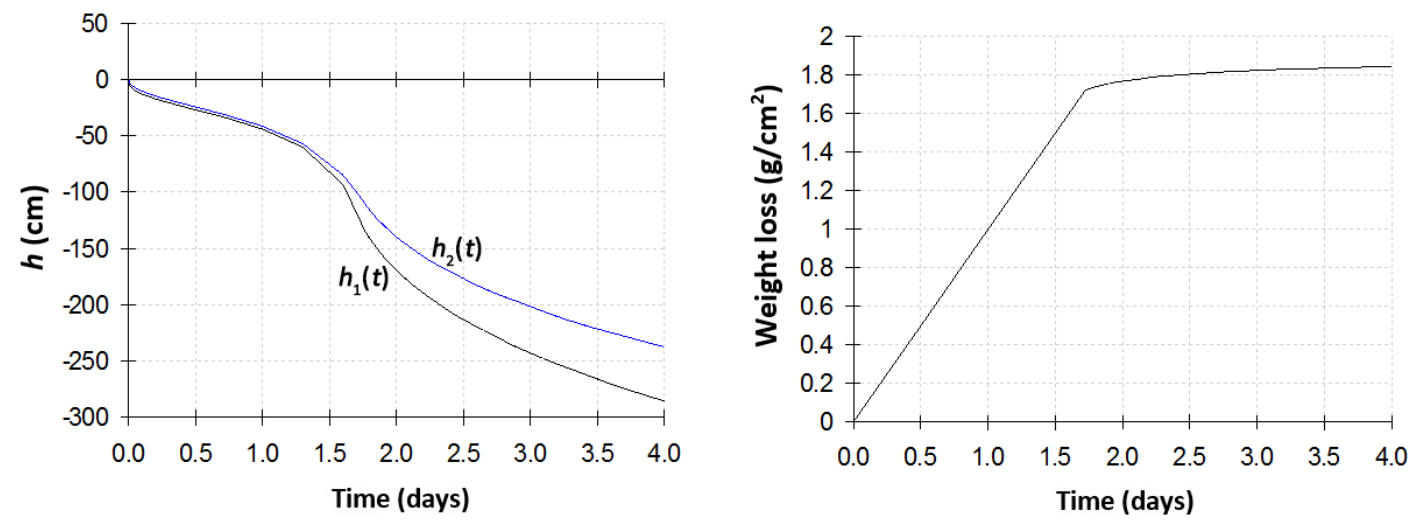

Water retention $\theta(\mathrm{pF})$
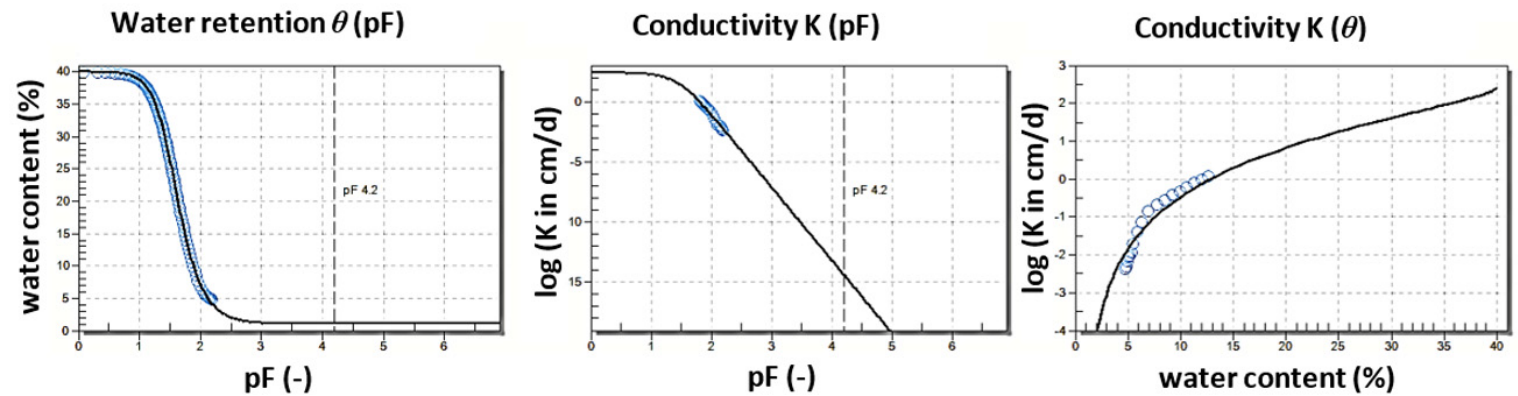

Fig. 4. HYDRUS-1D predictions of the pressure heads $h_{1}(t)$ and $h_{2}(t)$ and the weight loss $W(t)$ (top plots) for the coarse-textured soil (C) obtained using the VG parameter values listed in Table 1, and plots of the HMS generated water retention and hydraulic conductivity data, together with the HYPROP-Fit estimated VG hydraulic functions using the parameters for case CH-1 (Table 2).

The coarse-textured soil similarly provided excellent results for soil water retention as shown by the lower left plot in Figure 4 and the HMS estimated retention parameters in Table 2. However, estimation of the hydraulic conductivity parameters $K_{s}$ and $L$ was relatively poor, with the correct values being overestimated by more than $100 \%$. However, fixing the value of $K_{s}$ to its correct values was found to produce very reasonable values of $L$. This shows the importance of obtaining independent estimates of the hydraulic conductivity at or near saturation for coarse-texture media. Our result for the very coarse medium (VC), to be presented later, further supported this conclusion. 
Water retention $(\mathrm{pF})$
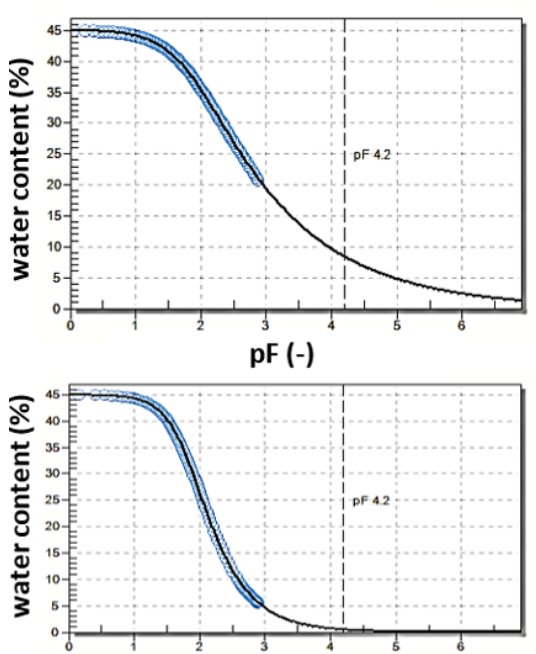

pF (-)

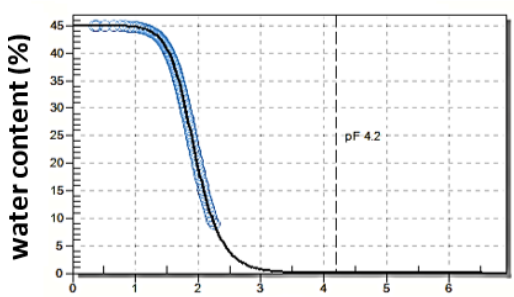

$\mathrm{pF}(-)$

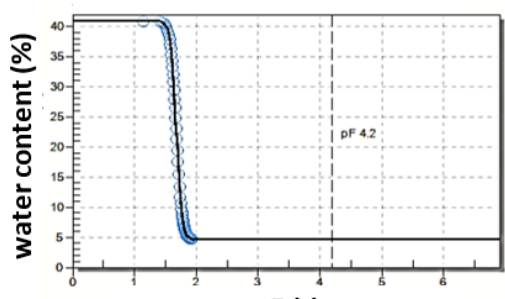

$\mathrm{pF}(-)$
Conductivity K (pF)

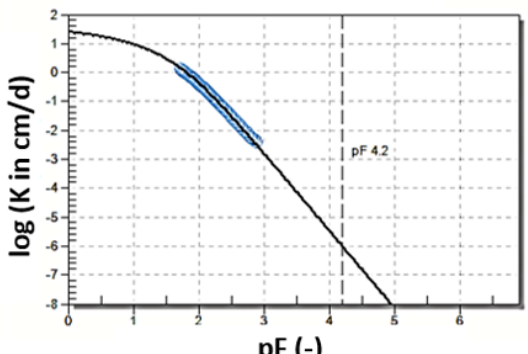

pF (-)

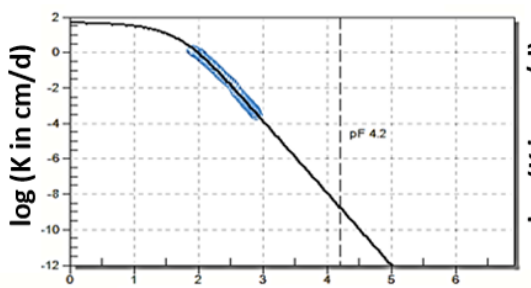

$\mathrm{pF}(-)$
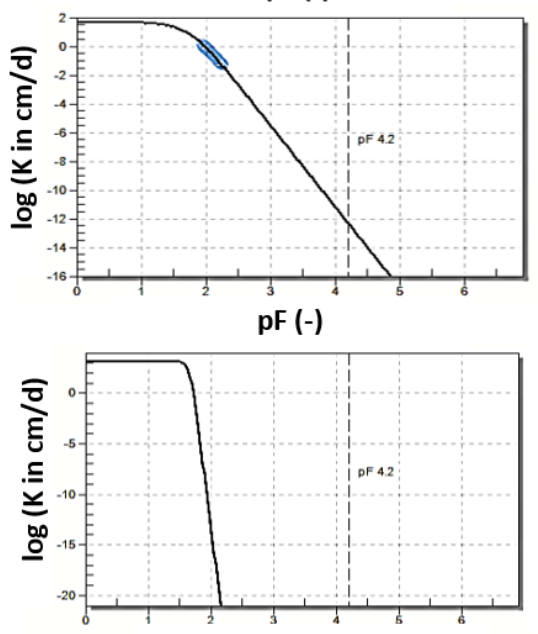

$\mathrm{pF}(-)$
Conductivity K $(\theta)$
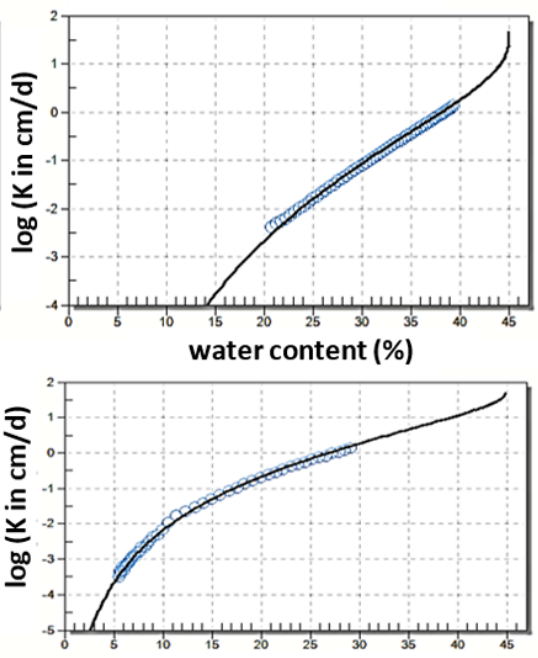

water content (\%)
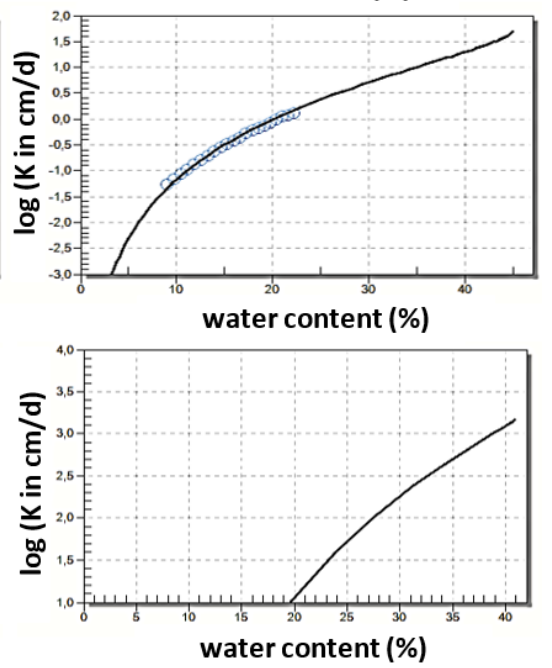

Fig. 5. HMS generated results for the hydraulic properties of the medium-textured soils assuming increasingly higher $n$ values indicative of more narrow pore-size distributions. The plots from top to bottom are for $n$ values of 1.3, 1.8, 2.5, and 10.0 representing cases $\mathrm{B}$, M, N and $\mathrm{VC}$ in Table 2, respectively.

Figures 2, 3 and 4 showed results for typical fine-, mediumand coarse-textured soils, with each case having different values of the van Genuchten $\alpha$ and $n$ parameters. We wanted to investigate more specifically the effects of varying $n$ values on the HMS results, while keeping $\alpha$ constant. When $n$ varies from small to large, the slope of the retention curve becomes increasingly steeper as the pore-size distribution becomes narrower. Figure 5 shows results when the value of $n$ value for the medium-textured soil varies from 1.3 (case B) to $1.8(\mathrm{M})$ to $2.5(\mathrm{~N})$. Not further included in this figure are the HYDRUS-1D predicted values of heads $h_{1}(t), h_{2}(t)$ and $W(t)$. However, the figure does contain results also for the very coarse medium (VC) having an extremely large $n$ value of 10.0. We note that $n$ values of above 10.0 or even higher are not uncommon for some soils (not necessarily coarse soils) such as golf course sands or other media such as quartz, carbonate sands and certain limestones (e.g., Sakaki et al., 2012; Wang et al., 2016).

The results in Figure 5 show excellent descriptions of the soil water retention curves of all four soils, but especially when $n$ increases to the VC case. Again, this was to be expected since the water retention data cover an increasingly narrower range of water contents. HMS estimated water retention data in all cases essentially duplicated the originally assumed synthetic values (Table 2). However, as $n$ increased, the descriptions of the hydraulic conductivity curves deteriorated, with the range of estimated conductivity values becoming increasingly smaller up to the VC case where HMS failed to produce any conductivity data. This indicates that the HMS procedure does not work well for the hydraulic conductivity when applied to soils having very narrow pore- or particle-size distributions.

We further tested HMS performance for several dualporosity soils whose hydraulic properties were described with Eqs. (3) and (4). Results more or less followed the conclusions obtained for the other soils in that they were most accurate when a wide range of water retention and pressure head data was covered by the tensiometers. Best results were again obtained for relatively small and intermediate values of $n$. Results for a typical case are shown in Figure 6, with the fitted dual-porosity parameters listed in Table 3. For some of the trials we again fixed the very dry end of the retention curve by assuming that other methods (e.g., WP4 dew point measurements) were used to define that part of the curve. The water retention parameters were estimated well, even when the value of the residual water content was also estimated using the HMS approach. The value of $K_{s}$ was also estimated well (Table 3 ). However, the tortuosity parameter $L$ was poorly estimated, even when $K_{s}$ was fixed at the original (synthetic) value of 50 $\mathrm{cm} /$ day. 
Table 2. Values of the HYPROP-Fit estimated soil hydraulic parameters for the various cases considered in this study. F, M, C and VC represent relatively fine, medium, coarse- and very coarse-textured soils, respectively, as referred to in Table 1 , while $\mathrm{B}, \mathrm{M}$ and $\mathrm{N}$ are medium-textured soils representing relatively broad to more narrow pore-size distributions. Assumed hydraulic parameters used in the HYDRUS simulations are in bold (see also Table 1), while the HYPROP-Fit generated parameters are identified with extra letters and numbers (e.g., FH-1 and FH-2).

\begin{tabular}{|c|c|c|c|c|c|c|c|c|}
\hline Case & Soil texture & $\theta_{s}\left(\mathrm{~cm}^{3} / \mathrm{cm}^{3}\right)$ & $\alpha\left(\mathrm{cm}^{-1}\right)$ & $n(-)$ & $K_{s}(\mathrm{~cm} /$ day $)$ & $L(-)$ & $R M S E(\theta)$ & $R M S E(\log K)$ \\
\hline & \multicolumn{8}{|c|}{ Effect of soil texture (fine to very coarse) } \\
\hline $\mathbf{F}$ & Fine & 0.500 & 0.008 & 1.30 & 10.0 & $\mathbf{0 . 5 0}$ & - & - \\
\hline FH-1 & Fine & 0.499 & 0.0074 & 1.32 & 8.37 & 0.27 & 0.0006 & 0.033 \\
\hline FH-2 & Fine & 0.500 & 0.0078 & 1.31 & $10.0 *$ & 0.42 & 0.0009 & 0.041 \\
\hline $\mathbf{M}$ & Medium & 0.450 & 0.016 & 1.80 & 50. & $\mathbf{0 . 5 0}$ & - & - \\
\hline MH-1 & Medium & 0.449 & 0.0154 & 1.83 & 47.8 & 0.48 & 0.0009 & 0.042 \\
\hline MH-2 & Medium & 0.449 & 0.0154 & 1.80 & $50.0 *$ & 0.51 & 0.0009 & 0.043 \\
\hline $\mathrm{C}$ & Coarse & 0.400 & 0.032 & 2.50 & 250. & 0.50 & - & - \\
\hline CH-1 & Coarse & 0.399 & 0.0318 & 2.59 & 812. & 1.16 & 0.0015 & 0.079 \\
\hline $\mathrm{CH}-2$ & Coarse & 0.398 & 0.0317 & 2.61 & $250 *$ & 0.56 & 0.0015 & 0.138 \\
\hline CH-3 & Coarse & $0.400^{*}$ & 0.0319 & 2.57 & $250 *$ & 0.58 & 0.0016 & 0.144 \\
\hline $\mathrm{VC}$ & Very coarse & 0.410 & 0.0219 & 10.0 & 1000. & 0.50 & - & - \\
\hline \multirow[t]{2}{*}{$\mathrm{VCH}-1$} & Very coarse & 0.410 & 0.0215 & 10.0 & $1000^{*}$ & 5.94 & 0.0001 & - \\
\hline & \multicolumn{8}{|c|}{ Effect of pore-size distribution (broad to narrow) } \\
\hline B & Broad & 0.450 & 0.016 & 1.30 & 50.0 & 0.50 & - & - \\
\hline BH-1 & Broad & 0.450 & 0.0153 & 1.31 & 39,6 & -0.04 & 0.0005 & 0.013 \\
\hline $\mathbf{M}$ & Medium & 0.450 & 0.016 & 1.80 & 50.0 & $\mathbf{0 . 5 0}$ & - & - \\
\hline MH-1 & Medium & 0.449 & 0.0154 & 1.83 & 47.8 & 0.48 & 0.0009 & 0.042 \\
\hline MH-2 & Medium & 0.449 & 0.0154 & 1.80 & $50.0^{*}$ & 0.51 & 0.0009 & 0.043 \\
\hline $\mathbf{N}$ & Narrow & 0.450 & 0.016 & 2.50 & 50.0 & 0.50 & - & - \\
\hline NH-1 & Narrow & 0.450 & 0.0157 & 2.52 & 38.4 & 0.19 & 0.0004 & 0.011 \\
\hline NH-2 & Narrow & 0.450 & 0.0157 & 2.52 & $50.0^{*}$ & 0.42 & 0.0004 & 0.029 \\
\hline
\end{tabular}

*Fixed parameter value in the HYPROP-Fit optimization

Table 3. Values of the assumed (DP) and HYPROP-Fit (DPH) estimated soil hydraulic parameters for the dual-porosity soil, and RMSE values of the optimizations.

\begin{tabular}{|c|c|c|c|c|c|c|c|c|c|c|c|}
\hline Case & $\begin{array}{c}\theta_{r} \\
\left(\mathrm{~cm}^{3} / \mathrm{cm}^{3}\right)\end{array}$ & $\begin{array}{c}\theta_{s} \\
\left(\mathrm{~cm}^{3} / \mathrm{cm}^{3}\right)\end{array}$ & $w_{1}$ & $\begin{array}{c}\alpha_{1} \\
\left(\mathrm{~cm}^{-1}\right)\end{array}$ & $\begin{array}{c}n_{1} \\
(-)\end{array}$ & $\begin{array}{c}\alpha_{2} \\
\left(\mathrm{~cm}^{-1}\right)\end{array}$ & $\begin{array}{c}n_{2} \\
(-)\end{array}$ & $\begin{array}{c}K_{s} \\
(\mathrm{~cm} / \text { day })\end{array}$ & $\begin{array}{c}L \\
(-)\end{array}$ & $\begin{array}{c}R M S E \\
(\theta)\end{array}$ & $\begin{array}{c}R M S E \\
(\log K)\end{array}$ \\
\hline DP & $\mathbf{0 . 1 0 0}$ & $\mathbf{0 . 5 0 0}$ & $\mathbf{0 . 5 0 0}$ & $\mathbf{0 . 2 0 0}$ & $\mathbf{2 . 5 0}$ & $\mathbf{0 . 0 0 2}$ & $\mathbf{2 . 0 0}$ & $\mathbf{5 0 . 0}$ & $\mathbf{0 . 5 0}$ & - & - \\
\hline DPH-1 & 0.119 & 0.504 & 0.553 & 0.214 & 2.15 & 0.002 & 2.15 & 43.6 & -0.083 & 0.0015 & 0.0334 \\
\hline DPH-2 & 0.111 & 0.504 & 0.448 & 0.216 & 2.15 & 0.002 & 2.09 & $50.0^{*}$ & 0.071 & 0.0015 & 0.0361 \\
\hline DPH-3 & 0.094 & $0.500^{*}$ & 0.484 & 0.203 & 2.25 & 0.002 & 1.95 & $50.0^{*}$ & 0.37 & 0.0015 & 0.0398 \\
\hline DPH-4 & 0.081 & $0.500^{*}$ & 0.503 & 0.202 & 2.28 & 0.002 & 1.88 & $50.0^{*}$ & $0.50^{*}$ & 0.0015 & 0.0422 \\
\hline
\end{tabular}

*Fixed parameter value in the HYPROP-Fit optimization
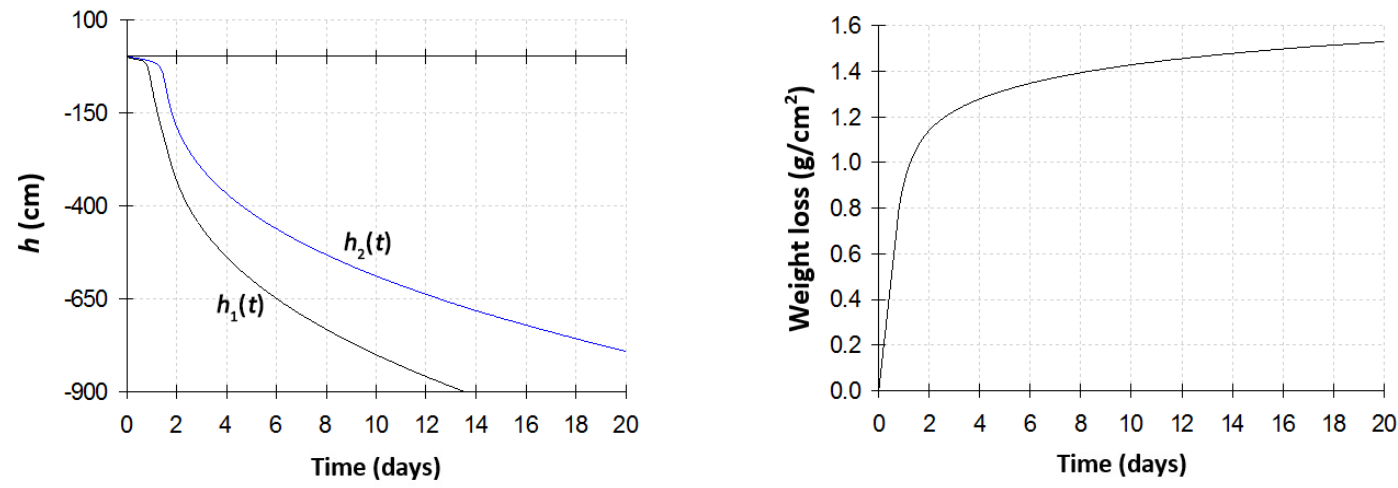

Water retention $\theta(\mathrm{pF})$
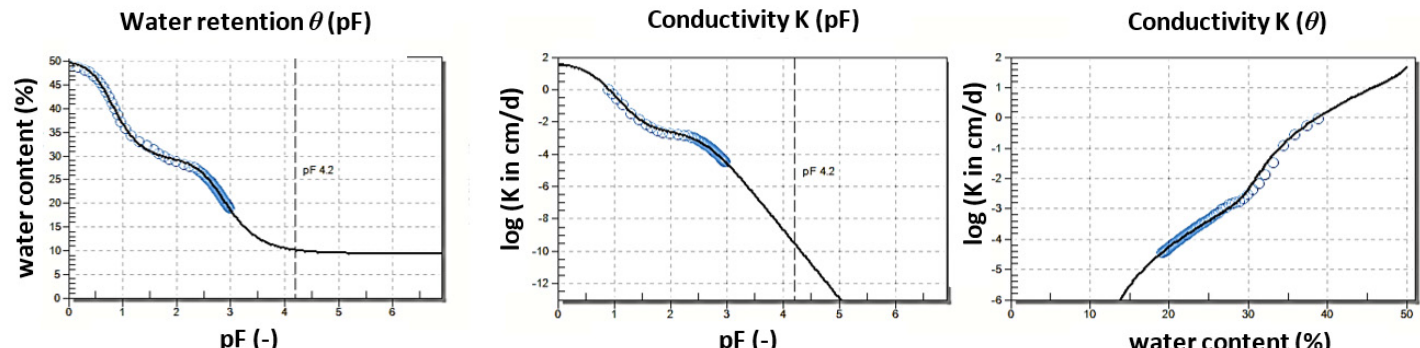

Fig. 6. HYDRUS-1D predictions of the pressure heads $h_{1}(t)$ and $h_{2}(t)$ and the cumulative weight loss $W(t)$ (top plots) for the dual-porosity soil (DP) obtained using the hydraulic parameter values listed in Table 3, and plots of the HMS generated water retention and hydraulic conductivity data, together with the HYPROP-Fit estimated dual-porosity functions using the parameters for case DPH-1 in Table 3. 
Overall, the dual-porosity examples indicate that reliable estimates will be obtained when the tensiometers and supporting equipment (possibly WP4) cover a complete range of retention data. Additional measurements of the saturated conductivity will help, especially for determining the pore connectivity parameter $L$. Still, we were very pleased with the results given the many DP parameters involved and their possible correlations.

We conclude that the HMS approach is a very attractive addition of the current suite of measurement approaches for the soil water retention and unsaturated hydraulic conductivity properties. We were especially impressed by the accuracy and completeness of the retention measurements, including for soils having narrow pore size distributions. The hydraulic conductivity measurements were in most cases very much acceptable also, especially for relatively fine- and medium-textured soils characterized by intermediate $\alpha$ and $n$ values.

\section{CONCLUDING REMARKS}

The evaporation method has long been used for estimating the drying branches of the soil hydraulic functions. The HYPROP measurement system (HMS) is rapidly becoming an increasingly popular alternative method for measurements of the soil water retention and unsaturated hydraulic conductivity properties. Our tests of the HMS approach parallel results obtained in two earlier studies (Peters and Durner, 2008; Peters et al., 2015) carried out to assess the accuracy of the HMS methodology by using the Richards equation to obtain synthetic date for use in the HMS analysis, and then to compare results against the original properties. Our analysis covered a very broad range of soils, including a soil with a very narrow poresize distribution as reflected by an $n$ value of 10.0. Accurate estimates were in most or all cases obtained for the soil water retention curve and its parameters, at least over the range of retention data used in the HMS analysis. The extremely coarse medium (VC) with $n=10$ gave excellent results for water retention, but failed for the hydraulic conductivity. Except for relatively fine and intermediate soil textures, most cases do still benefit from independent estimate of the hydraulic conductivity at and/or near saturation. Overall, the HMS methodology performed very well and as such constitutes a much-needed addition to current soil hydraulic measurement techniques.

\section{REFERENCES}

Arya, L.M. 2002. Wind and hot-air methods. In: Dane, J.H., Topp, G.C. (Eds.): Methods of Soil Analysis. Part 4. Physical Methods. Soil Sci. Soc. Am., Madison, WI, pp. 916-920.

Assouline, S., Tessier D., Bruand, A., 1998. A conceptual model of the soil water retention curve. Water Resour. Res., 34, 2, 223-231.

Becher, H.H., 1970. Ein Verfahren zur Messung der ungesattigten Wasserleitfahigkeit. Z. Pflanzenernaehrung u. Bodenkd., 128, 1-12. (In German.)

Bertuzzi, P., Voltz, M., 1997. The Wind method: A standard laboratory method adopted by the French INRA laboratories. In: Proc. Workshop The use of pedotransfer in soil hydrology research, Orleans, France, pp. 51-53.

Bittelli, M., Flury, M., 2009. Errors in water retention curves determined with pressure plates. Soil Sci. Soc. Am. J., 73, 1453-1460. DOI: 10.2136/sssaj2008.0082.

Bitterlich, S., Durner, W., Iden, S.C., Knabner, P., 2004. Inverse estimation of the unsaturated soil hydraulic properties from column outflow experiments using free-form parameterizations. Vadose Zone J., 3, 971-981.

Brooks, R.H., Corey, A.T., 1964. Hydraulic properties of porous media. Hydrology paper 3. Colorado State Univ., Fort Collins, CO.

Dane, J.H., Hopmans, J.W., 2002. Soil water retention and storage. In: Dane, J.H., Topp, G.C. (Eds.): Methods of Soil Analysis. Part 4. Physical Methods. Soil Sci. Soc. Am., Madison, WI, pp. 675-720.

Dane, J.H., Topp, G.C. (Eds.), 2002. Methods of Soil Analysis. Part 4. Physical Methods. Soil Sci. Soc. Am., Madison, WI.

Durner, W., 1994. Hydraulic conductivity estimation for soils with heterogeneous pore structure. Water Resour. Res., 32, 9, 211-223.

Fredlund, D.G., Xing, A., 1994. Equations for the soil water characteristic curve. Can. Geotechn. J., 31, 521-532.

Gardner, W.R., Miklich, F.J., 1962. Unsaturated conductivity and diffusivity measurements by a constant flux method. Soil Sci., 93, 271-274.

Gubiani, P.I., Reichert, J.M., Campbell, C., Reinert, D.J., Gelain, N.S., 2012. Assessing errors and accuracy in dew-point potentiometer and pressure plate extractor measurements. Soil Sci. Soc. Am. J., 77, 1, 19-24. DOI: 10.2136/sssaj2012.0024.

Halbertsma, J., 1996. Wind's evaporation method; determination of the water retention characteristics and unsaturated hydraulic conductivity of soil samples. Possibilities, advantages and disadvantages. In: European Workshop on Advanced Methods to Determine Hydraulic Properties of Soils, Thurnau, Germany, 10-12 June 1996. Department of Hydrology, University of Bayreuth, $107 \mathrm{p}$.

Hopmans, J.W., Šimůnek, J., Romano, N., Durner, W., 2002. Inverse modeling of transient water flow. In: Dane, J.H., Topp, G.C. (Eds.): Methods of Soil Analysis. Part 4. Physical Methods. SSSA, Madison, WI, pp. 963-1008,

Iden, S.C., Durner, W., 2008. Free-form estimation of soil hydraulic properties using Wind's method. Europ. J. Soil Sci., $\quad 59, \quad 6, \quad 1228-1240$. DOI:10.1111/j.13652389.2008.01068.x.

Iden, S.C., Durner, W., 2014. Comment to "Simple consistent models for water retention and hydraulic conductivity in the complete moisture range" by A. Peters. Water Resour. Res., 50, 7530-7534.

Kastanek, F.J., Nielsen, D.R., 2001. Description of soil water characteristics using cubic spline interpolation. Soil Sci. Soc. Am. J., 65, 279-283.

Klute, A. (Ed.), 1986. Methods of Soil Analysis. Part 1. Physical and Mineralogical Methods. 2nd ed. Am. Soc. Agron., Madison, WI, pp. 1025-1054.

Klute, A., Dirksen, C., 1986. Hydraulic conductivity and diffusivity: laboratory methods. In: Klute, A. (Ed.), Methods of Soil Analysis. Part 1. Physical and Mineralogical Methods. 2nd ed. Agron. Monogr. 9. ASA, Madison, WI, pp. 687-734.

Kool, J.B., Parker J.C., Genuchten, M.Th., 1987. Parameter estimation for unsaturated flow and transport models, a review. J. Hydrol., 91, 255-293.

Kosugi, K., 1996. Lognormal distribution model for unsaturated soil hydraulic properties. Water Resour. Res., 32, 2697-2703.

Looney, B.B., Falta, R.W. (Eds.), 2000. Vadose Zone Science and Technology Solutions. Battelle Press, Columbus, $\mathrm{OH}$, $1540 \mathrm{p}$.

Mualem, Y., 1976. A new model for predicting the hydraulic conductivity of unsaturated porous media. Water Resour. Res., $12,513-522$. 
Nimmo, J.R., Perkins, K.S., Lewis, A.M., 2002. Steady-state centrifuge. In: Dane, J.H., Topp, G.C. (Eds.): Methods of Soil Analysis. Part 4. Physical Methods. SSSA Book Ser. 5, SSSA, Madison, WI, pp. 903-916.

Pertassek, T., Peters, A., Durner, W., 2015. HYPROP-FIT Software User's Manual, V.3.0. UMS GmbH, Munich, Germany, $66 \mathrm{p}$.

Peters, A., 2013. Simple consistent models for water retention and hydraulic conductivity in the complete moisture range. Water Resour. Res., 49, 6765-6780.

Peters, A., 2014. Reply to comment by S. Iden and W. Durner on Simple consistent models for water retention and hydraulic conductivity in the complete moisture range. Water Resour. Res., 50, 7535-7539.

Peters, A., Durner, W., 2008. Simplified evaporation method for determining soil hydraulic properties. J. Hydrol., 356, 147162.

Peters, A., Iden, S.C., Durner, W., 2015. Revisiting the simplified evaporation method: Identification of hydraulic functions considering vapor, film and corner flow. Journal of Hydrology, 527, 531-542.

Plagge, R., 1991. Bestimmung der ungesättigten Wasserleitfähigkeit im Boden. Ph.D. diss. Dep. Landschaftsentwicklung, Techn. Univ. Berlin, Berlin. (In German.)

Priesack, E., Durner, W., 2006. Closed-form expression for the multimodal unsaturated conductivity function. Vadose Zone J., 5, 121-124. DOI:10.2136/vzj2005.0066.

Sakaki, T., Limsuwat, A., Cihan, A., Frippiat, C., Illangasekare, T.H., 2012. Water retention in a coarse soil pocket under wetting and drainage cycles. Vadose Zone J., 11, 1. DOI: 10.2136/vzj2011.0028.

Scanlon, B.R., Andraski, B.J., Bilskie, J., 2002. Miscellaneous methods for measuring matric or water potential. In: Dane, J.H., Topp, G.C. (Eds.): Methods of Soil Analysis. Part 4. Physical Methods, Chapter 3.3. Soil Sci. Soc. Am., Madison, WI, pp. 642-670.

Schelle, H., Iden, S.C., Peters, A., Durner, W., 2010. Analysis of the agreement of soil hydraulic properties obtained from multistep-outflow and evaporation methods. Vadose Zone J., 9, 1080-1091. DOI: 10.2136/vzj2010.0050.

Schindler, U., von Unold, G., Durner, W., Müller, L., 2010a. Evaporation method for measuring unsaturated hydraulic properties of soils: extending the range. Soil Sci. Soc. Am. J., 74, 1071-1083. DOI: 10.2136/sssaj2008.0358.

Schindler, U., Durner, W., von Unold, G., Müller, L., Wieland, R., 2010b. The evaporation method: extending the measurement range of soil hydraulic properties using the air-entry pressure of the ceramic cup. J. Plant Nutr. \& Soil Sci., 173, 563-572. DOI: $10.1002 /$ jpln.200900201.

Šimůnek, J., Wang, D., Shouse, P.J., van Genuchten, M.Th., 1998a. Analysis of field tension disc infiltrometer data by parameter estimation. Int. Agrophysics, 12,167-180.

Šimůnek, J., Wendroth, O., van Genuchten, M.Th., 1998b. A parameter estimation analysis of the evaporation method for determining soil hydraulic properties. Soil Sci. Soc. Am. J., 62, 4, 894-905.

Šimůnek, J., van Genuchten, M.Th., Šejna, M., 2016. Recent developments and applications of the HYDRUS computer software packages. Vadose Zone J., 15, DOI: 10.2136/vzj2016.04.0033.

van Dam, J.C., Stricker, J.N.M., Droogers, P., 1994. Inverse method to determine soil hydraulic functions from multistep outflow experiments. Soil Sci. Soc. Am. J., 58, 3, 647-652.

van Genuchten, M.Th., 1980. A closed-form equation for predicting the hydraulic conductivity of unsaturated soils. Soil Sci. Soc. Am. J., 44, 892-898.

van Genuchten, M.Th., Leij, F.J., Yates, S.R., 1991. The RETC code for quantifying the hydraulic functions of unsaturated soils. Report EPA/600/2-91/065. U.S. Environmental Protection Agency, Ada, OK.

Wang, S., Tokunaga, T.K., Wan, J., Dong, W., Kim, Y., 2016. Capillary pressure-saturation relations in quartz and carbonate sands: Limitations for correlating capillary and wettability influences on air, oil, and supercritical CO2 trapping, Water Resour. Res., 52, DOI: 10.1002/2016WR018816.

Wendroth, O., Ehlers, W., Hopmans, J.W., Klage, H., Halbertsma, J., Wösten, J.H.M., 1993. Reevaluation of the evaporation method for determining hydraulic functions in unsaturated soils. Soil Sci. Soc. Am. J., 57, 1436-1443.

Wind, G.P., 1968. Capillary conductivity data estimated by a simple simple method for determining soil hydraulic properties in the method. In: Rijtema, P.E., Wassink, H. (Eds.): Proc. Wageningen Symp. Water in the Unsaturated Zone. Vol. 1. June 1966. Int. Assoc. Scientific Hydrol., Gentbrugge, Belgium, pp. 181-191.

Wraith, J.M., Or, D., 1998. Nonlinear parameter estimation using spreadsheet software. J. Nat. Resour. Life Sci. Educ., 27, 13-19.

Zhuang, L., Bezerra Coelho, C.R., Hassanizadeh, S.M., van Genuchten, M.Th., 2017. Analysis of the hysteretic hydraulic properties of unsaturated soil. Vadose Zone J., 16, 5. DOI: 10.2136/vzj2016.11.0115.

Note: Colour version of Figures can be found in the web version of this article. 